The bowels became regular. This favourable symptom must be put down to abdominal massage, as podophyllin had been exhibited beforehand without the wished-for result. Unfortunately in my part of the country medical men advise massage for nearly every ill that man is heir to, and thereby bring a wonderful remedy for good into bad repute. During the last twelve months about a dozen cases in all of severe bysteria, neurasthenia, and chronic dyspepsia have come under my personal care, and they have all been cured by massage and proper feeding without medicine, cases in which dosing was previously so systematic as to become almost second nature.

\section{Clinical ates:}

\section{MEDICAL, SURGICAL, OBSTETRICAL, AND THERAPEUTICAL.}

\section{NOXIOUS SALTS OF TIN IN FRUITS PREPARED IN TIN VESSELS,}

By Leonaro W. Sedgwick, M.D.

THE harmlessness of the salts of tin other than the chlorides is generally taken for granted, but the following facts appear to show that the assumption is incorrect.

In October, 1886, I saw nine persons in one wellmanaged, healthy housebold simultaneously suffering from watery diarrhœa, sickness, and great pain in the abdomen. A close investigation served to show that, excluding the water they drank (which was pure) and the air they breathed (which was free from drain contamination), there was one thing, and one thing only, they had done in common, and that was the eating of pears stewed in a newly tinned copper pan. It came out, too, that many of them had suffered from two or three similar attacks on previous days, and that these attacks had all occurred on days when they had eaten stewed pears. I therefore obtained some pears so cooked, and, on testing the juice, found it laden with tin salts, but containing no copper. That the diarrhoa gave way in a short time to simple remedies, that the drainage and the water supply of the bouse were perfect, that the eating of stewed pears preceded on the same day each attack of illnese, and that pears similarly stewed were found to contain large quantities of tin saits, were to my mind conclusive, if circumstantial, evidence that the attacks of diarrhoa were caused by the tin salts. And then occurred the thought that, if the cooking of a somewhat acid fruit for a short time in a tinned vessel effected the formation of a poisonous salt of tin, the keeping of an acid fruit for months in a tin can must have a like result. I therefore tested the contents of cans of apricots, pine-apples, peaches, and tomatoss, and in every instance found a large amount of a salt of tin. In this I was confirmed by my friend Mr. Hugh Power, who also in one specimen detected a salt of zinc. Since then I have seen several instances where painful diarrhoe followed the eating of a tinned fruit, especially in one case, where tinned pine-apple was eaten by several persons, who all suffered in like manner. And so I am compelled to believe that many cases of casual and unexplained nausea and diarrbœe are caused by the use of tinned fruit. Indeed, since the occurrence of the cases in 1886 , I have lost no opportunity of relating these things to my personal acquaintances, and of advocating the use of bottled fruits only.

\section{PERICHONDRITIS OF THE LARYNX; TRACHEOTOMY RECOVERY.}

By Francis Hollinshead, M.R.C.S., L.S.A.

THE following particulars of a case which occurred in my practice eight years ago may be of some practical interest at the present time.

R. W-_, aged thirty-nine, pointsman on the Midland Railway, consulted me for a troublesome hoarse cough, attended with difficulty in breathing. $\mathrm{He}$ had all the symptoms of a severe attack of laryngeal catarrh, and was treated by poultices and counter-irritation, together with the usual remedies and inhalatione. The case continued to get worse, the difficulty of breathing increased, and the patient could only articulate in a whisper. On laryngoscopic examination, the lary $\mathrm{nx}$ was found red, swollen, and ulcerated; there were also thickening and tenderness externally. The patient was now put on large doses of perchloride of mercury, with iodide of potassium and cinchona, and at the same time he was kept in a warm atmosphe $e_{\text {, }}$ the inhalations being continued. There being no signs of improvement, Dr. (now Sir) Walter Foster saw the patient in consultation with me. He advised the continuance of the treatment, but to be in readiness to perform tracheotomy should the symptoms of dyspnoea increase. The man continued to get worse, and on the following morning at 5 A.M. I found him so bad, with suffocation impending, that, with the aid of my then assistant, Mr. Welch, I immediately opened the trachea and inserted a tube. The result was immediate relief of the patient's suffering; from being cyanosed, he recovered all power of breathing, became calm, and natural in colour. I kept bim in a warm atmosphere, with hot sponges over the orifice of the tube, constantly reapplied, and continued the medicinal treatment as before. The case went on well, the cough gradually lessened, and the thickening of the laryn and ulceration subsided. Later on a piece of exfoliated cartilage was coughed up, the expectoration daily diminished, and at the end of two months from the operation I deemed it advisable to make an attempt to do without the tube. I first experimented by removing it for a few hours, keeping the patient under close observation the whole time. Finding that he did not get worse, I allowed him to remain without it, and at the expiration of one month from the removal of the cannula the external wound had healed and he continued to breathe quite freely. This patient is still alive and has had no return of the disease, and but for some feebleness of voice is quite well.

The success of this case appeared to me to be due to the removal of the cannula at the time when the larynx had so far recovered as to enable the patient to breathe fairly well without it, as the pressure of it, acting as a foreign body, seemed to set up some irritation in the trachea, causing exuberant granulations to appear around the orifice of the wound.

\section{ON THE TREATMENT OF CARBUNCLE BY CARBOLISED} SPRAY.

By H. BLANe, M.D , F.R.C.P.

Prof. Fernetrl, at the meeting of the Academy of Medicine of Paris held on January 17th last, made an interesting communication on the treatment of carbuncle by carbolised spray. ${ }^{1}$ He stated that in 1883 , in a severe case of carbuncle, he directed that carbolised spray be frequently applied in order to thoroughly disinfect the parts previously to an operation being performed. To his surprise, he found that under the use of the carbolised spray such improvement had declared itself that surgical interference became unnecessary. Henceforth he exclusively resorted to the carbolised spray in all cases of carbuncle. Whether they were large or small, painful or indolent, complicated or not with diabetes, previously opened by surgery, by sloughing, or with the skin as yet unbroken, in every case the same local treatment was applied, and always with a successful result.

Prof. Verneuil prefers the steam spray. The larger the carbuncle and the more perfect the skin, the more powerful the apparatus does he select. He places the apparatus a short distance (about ten inches) from the diseased parts, regulating the intensity of the spray according to the feelings of the patient. Usually he allows the spray to reach the parts unprotected; occasionally, however, he covers them with a layer of muslin. He employs a 2 per cent. solution of carbolic acid, and applies the spray three or four times daily, for about twenty minutes each time. Botween the sittings he dresses the carbuncle with lint soaked in carbolic acid solution of the same strength. He is careful to protect the parts around the carbuncle from the action of the spray.

Shortly after reading an account of Prof. Verneuil's treatment a severe case of carbuncle was admitted under my care iato the Protestant Hospital of Cannes, and as the patient 